\title{
Ocorrência e potencial biotecnológico de leveduras associadas aos frutos de Attalea speciosa mart ex Spreng
}

\author{
Stella Costa Santos do VALE ${ }^{[1]}$, Ana Paula Martins GUIMARÃES ${ }^{[1]}$ e Paula Benevides de MORAIS ${ }^{[2]}$ \\ ${ }^{[1]}$ Programa de Pós-Graduação em Ecologia de Ecótonos, Núcleo de Estudos Ambientais, Universidade Federal do Tocantins, Rua 03, Quadra 17, \\ Jardim dos Ipês, s/n, Caixa Postal 136, CEP 77500-000, Porto Nacional-TO, Brasil. Laboratório de Microbiologia Ambiental e Biotecnologia. \\ Avenida NS 15, 109 Norte - Plano Diretor Norte, 77001-090. Palmas-TO, Brasil. E-mail: stellacsantos@ hotmail.com; biologa.apmg@gmail.com \\ ${ }^{[2]}$ Professora do programa de Pós-Graduação Doutorado em Biodiversidade e Biotecnologia da Amazônia Legal (BIONORTE). Laboratório de \\ Microbiologia Ambiental e Biotecnologia. Avenida NS 15, 109 Norte - Plano Diretor Norte, 77001-090. Palmas-TO, Brasil. E-mail: \\ moraispb@uft.edu.br

\begin{tabular}{|c|c|}
\hline & \\
\hline & \multirow{11}{*}{$\begin{array}{l}\text { Attalea speciosa Mart ex. Spreng é uma palmeira oleaginosa pertencente à família } \\
\text { Arecaceae e seus frutos possuem } 15 \% \text { do peso total correspondente ao epicarpo; } 20 \% \\
\text { ao mesocarpo e } 58 \% \text { ao endocarpo (incluindo as amêndoas), sendo a amêndoa o } \\
\text { componente mais utilizado. Os frutos representam importantes micro-habitats naturais } \\
\text { para uma diversidade significativa de espécies de leveduras. O objetivo deste trabalho } \\
\text { foi isolar e testar as habilidades enzimáticas de linhagens de leveduras associadas as } \\
\text { amêndoas de Attalea speciosa, e seu possível potencial biotecnológico para utilização } \\
\text { com fins industriais. Foram realizadas } 10 \text { coletas de amostras com } 15 \text { amêndoas cada, } \\
\text { com sete dias de intervalo entre cada uma, em um ecossistema de Mata de Babaçuais. } \\
\text { Entre } 84 \text { linhagens de leveduras. A atividade enzimática foi avaliada e dentre as oitenta } \\
\text { e quatro linhagens de leveduras testadas quanto a capacidades de hidrolisar a caseína } \\
\text { em meio protease, } 26,04 \% \text { apresentaram potencial enzimático em pH ácido, } 31,92 \% \\
\text { em pH neutro e } 28,56 \% \text { em pH alcalino, demonstrando potencial enzimático em } \\
\text { diferentes pHs.Sessenta e duas linhagens produtores de lipases podem ter uso potencial } \\
\text { para testes de emprego comercial de lipases microbianas. Já a atividade celulolítica foi } \\
\text { mais limitada, apenas dezenove linhagens se mostraram degradadoras de celulose } \\
\text { microcristalina. }\end{array}$} \\
\hline & \\
\hline & \\
\hline & \\
\hline & \\
\hline & \\
\hline & \\
\hline & \\
\hline 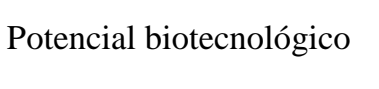 & \\
\hline & \\
\hline & \\
\hline
\end{tabular}

\section{Occurrence and biotechnological potential of yeasts associated with almond fruits of Attalea Speciosa mart ex Spreng.}

\begin{abstract}
Attalea speciosa Mart ex Spreng is a oil palm belonging to the family Arecaceae with fruits $15 \%$ of the total weight of the fruit correspond to the epicarp; $20 \%$ to $58 \%$ to the mesocarp and endocarp (including almonds), the almonds being its most used component. Fruits are important natural microhabitats for a significant diversity of yeast species. The objective of this study was to isolate and test the enzymatic abilities of yeast strains associated with almond fruits of Attalea speciosa, and their possible biotechnological potential for industrial purposes. Ten collections of 15 almonds for sample were conducted at seven days intervals at an extractivism reserve of Mata de Babaçuais ecosystem. Among 84 yeasts isolated, The enzymatic activity was evaluated and among the eighty-four strains of yeast tested as the ability to hydrolyze casein among protease, $26.04 \%$ had enzymatic potential acidic $\mathrm{pH}, 31.92 \%$ at neutral $\mathrm{pH}$ and $28.56 \%$ in alkaline $\mathrm{pH}$, demonstrating enzyme potential in different $\mathrm{pHs}$.A lipase activity was also satisfactory where, sixty-two lipase producing strains may have potential use for commercial employment testing microbial lipases. Already cellulolytic activity was more limited, only nineteen lineages showed degrading cellulose.
\end{abstract}

Index terms: microorganisms, enzymes, biotechnological potential

c) (i) (5) Copyright: (C) 2015 JBFS all rights. This is an open-access article distributed under the terms of the Creative Commons Attribution License, which permits unrestricted use, distribution, and reproduction in any medium, provided the original author and source are credited.

Financiamento: Os autores agradecem o apoio financeiro do Conselho Nacional de Desenvolvimento Científico e Tecnológico, através do Processo 45443/2012-0

Conflito de interesse: Os autores declaram que não há conflito de interesse.

Como referir esse documento (ABNT):

VALE, S. C. S.; GUIMARÃES, A. P M.; MORAIS, P. B Ocorrência e potencial biotecnológico de leveduras associadas aos frutos de Attalea speciosa mart ex Spreng. Journal of Bioenergy and Food Science, Macapá, v.2, n.4, p.213-225, out./dez., 2015. http://dx.doi.org/10.18067/jbfs.v2i4.77 


\section{INTRODUÇÃO}

O Babaçu (Attalea speciosa Mart ex. Spreng), é uma palmeira oleaginosa pertencente à família Arecaceae, espécie nativa do Brasil, com maior distribuição nos estados do Maranhão, Piauí, Tocantins [1]. Pode ocorrer em florestas ou campos abertos, sendo, porém mais freqüentemente encontrado em áreas antropizadas, após colonizar antigas formações desmatadas [2]. Segundo Rosenthal [3], das partes que compõem o fruto do babaçu, $15 \%$ do peso total do fruto correspondem ao epicarpo; $20 \%$ ao mesocarpo e $58 \%$ ao endocarpo (incluindo as amêndoas), sendo a amêndoa sua componente mais utilizada, pois a partir dela se obtém o óleo (rico em ácidos láuricos), que apresenta diversos usos, dentre eles a fabricação de combustíveis, lubrificantes, sabão, sabonete e cosméticos [4].

As leveduras são fungos não filamentosos que não apresentam corpos de frutificação em seu estágio sexual, possuem crescimento vegetativo que pode ser por brotamento ou fissão, são unicelulares e não apresentam mobilidade, sendo em sua maioria saprofíticas e algumas parasitas oportunistas [5, 6]. Dentre todos os órgãos dos vegetais em que há registro da existência de leveduras, estão inclusos os frutos, que apresentam uma diversidade microbiológica que não depende somente das propriedades físico-químicas de cada espécie, estando relacionada também a aspectos ambientais da região, tais como temperatura [7], oxigênio e disponibilidade de água [8].

Enzimas, de uma maneira geral podem ser obtidas a partir de diversas fontes distintas [9], dentre as quais as de origem microbiana se destacam por reunirem uma série de vantagens, onde os mais citados para a obtenção de enzimas se encontram as leveduras e fungos [9], sendo que a obtenção de enzimas a partir de leveduras apresenta vantagens devido a diversidade de substratos e a velocidade de crescimento das mesmas. Sendo assim objetivo deste trabalho foi isolar e testar as habilidades enzimáticas de linhagens de leveduras associadas aos frutos de Attalea speciosa, e seu possível potencial biotecnológico para utilização com fins industriais.

\section{MATERIAL E MÉTODOS}

\section{a) Coleta e processamento das amostras}

As coletas foram realizadas em 3 áreas de extrativismo do Município de Araguaína, Estado do Tocantins. As amêndoas do babaçu foram compradas das quebradeiras de coco que atuam na região. Foram realizadas 10 coletas, com intervalos de 7 dias entre as coletas. Padronizou-se o esforço amostral de 15 castanhas por cada coleta com um total de 150 castanhas para a realização completa do experimento.

As castanhas foram armazenadas em sacos plásticos e levadas ao Laboratório de Microbiologia Ambiental e Biotecnologia da Fundação Universidade Federais do Tocantins, Campus de Palmas para serem processadas.

As amêndoas de cada coleta foram divididas em 3 amostras (5 amêndoas em cada amostra). Para se obter as leveduras presentes nas castanhas do babaçu, foi utilizada a metodologia de imersão e descanso em $100 \mathrm{ml}$ de água destilada com $0,1 \%$ de Tween a $80 \%$. Foram feitas 3 repetições desta solução em cada processamento, e depositadas em frascos de vidro tipo erlenmeyer (3 frascos), para serem esterilizadas em autoclave a $121^{\circ} \mathrm{C}$. Em cada erlenmeyer contendo a solução de Tween foram depositadas 5 amêndoas que permaneceram nesta solução por 30 minutos, realizando movimentos circulares a cada 5 minutos para a dissociação das leveduras presentes nas amêndoas. Logo após o tempo previsto a solução foi diluída em água peptonada (1:10), que foram semeadas em triplicata pela técnica de espalhamento de superfície em meio Dicloran Rosa de Bengala (peptona 5,0 g/l, glicose $10,0 \mathrm{~g} / \mathrm{l}$, fosfato de monopotássico $1,0 \mathrm{~g} / \mathrm{l}$, sulfato de magnésio $0,5 \mathrm{~g} / \mathrm{l}$, dicloran 0,002 , rosa de bengala, Agar 15,0 g/l, pH 5,6 0 0,2), acrescido de 0,04\% de Clorofenicol e incubadas em B.O.D a $25^{\circ} \mathrm{C}$ por 7 dias. Durante o período de incubação as colônias de leveduras que apresentavam crescimento, foram contadas, descritas e isoladas em YMA (ágar 2,0\%, extrato de levedura $0,3 \%$, peptona $0,5 \%$, glicose $1,0 \%$, extrato de malte $0,3 \%$ ) adicionado de cloranfenicol $0,04 \%$. A descrição das colônias baseou-se nas características morfológicas que apresentaram, como: elevação, tamanho, formato das bordas, cor e aspecto [10], e registradas com os dados de procedência (ambiente e data de coleta).

As colônias puras foram armazenadas seguindo as recomendações de criopreservação propostas por Kirsop e Kurtzman [12], sendo repicadas em meio líquido GYMP (glicose 2\%, extrato de levedura $0,5 \%$, extrato de malte $1 \%$ e fosfato monobásico de sódio $0,2 \%$ ) em tubos de vidro, e incubadas a $28^{\circ} \mathrm{C}$ por 24 horas. Ao decorrer o tempo de incubação, os isolados que apresentaram turvação no meio de cultura foram depositados em tubos criogênicos acrescidos de $20 \%$ de glicerol puro, para em seguida serem armazenados em 
freezer a $-80^{\circ} \mathrm{C}$ e mantidos congelados até a realização dos testes de produção de enzimas e identificação molecular.

\section{b) Identificação molecular (extração de DNA e PCR)}

A extração do material genético foi realizada de acordo com o descrito por Querol et al. [13], com adaptações, utilizando-se de colônias puras e de crescimento recente (no máximo 48h). Foi resuspendida uma alçada de cada colônia em $100 \mu \mathrm{L}$ de tampão de lise (Tris-HCl 0,05M, EDTA 0,005M, $\mathrm{NaCl} 0,1 \mathrm{M}$ e SDS $1 \%$ ) em tubos do tipo eppendorf de $1,5 \mathrm{ml}$. Em seguida foram incubadas em banhomaria a $65^{\circ} \mathrm{C}$ por 30 minutos. Ao fim do tempo de incubação, adicionou-se $200 \mu \mathrm{L}$ de clorofórmio álcool isoamílico (24:1), homogeneizando por inversão (20 vezes). As amostras foram centrifugadas a $14.000 \mathrm{rpm}$ por 15 minutos.

Retirou-se o sobrenadante de cada amostra, transferindo-o para outro tubo eppendorf estéril. Em seguida adicionou-se isopropanol (v/v) e os tubos foram deixados em repouso por 15 minutos. Após o período de repouso os tubos foram levados novamente para a centrífuga por mais 10 minutos a $14.000 \mathrm{rpm}$ e em seguida descartou-se o sobrenadante por inversão. $\mathrm{Na}$ sequência, adicionou-se aos tubos $200 \mu \mathrm{L}$ de etanol $70 \%$ gelado e novamente as amostras foram levadas para a centrífuga por 10 minutos a $14.000 \mathrm{rpm}$, e o sobrenadante descartado por inversão.

Os tubos foram deixados abertos e cobertos com papel alumínio overnight em temperatura ambiente para possibilitar total evaporação do álcool. No dia seguinte o DNA foi re-suspendido em $50 \mu \mathrm{L}$ de TE (Tris-HCl $10 \mathrm{mM}$, EDTA $0,1 \mathrm{mM}$, $\mathrm{pH} 8$ ) para ser hidratado e estocado em freezer a $20^{\circ} \mathrm{C}$

Para o agrupamento por PCR fingerprinting utilizou-se o iniciador específico EI1, segundo o protocolo descrito por De Barros et al. [14], e eletroforese em gel de agarose 1,5\%.

Utilizou-se $5 \mu \mathrm{L}$ de tampão de PCR 10X, 1,5 $\mu \mathrm{L}$ de $\mathrm{MgCl}_{2}$ a $25 \mathrm{mM}, 1,0 \mu \mathrm{L}$ de dNTP $10 \mathrm{mM}$ cada, $2,0 \mu \mathrm{L}$ do iniciador EI1 a 10 pmol, $0,2 \mu \mathrm{L}$ de Taq DNA polimerase a $5 \mathrm{u} / \mu \mathrm{L}, 1 \mu \mathrm{L}$ de DNA 100 $300 \mathrm{ng} / \mu \mathrm{L}$ com volume final complementado com água ultrapura para $25 \mu \mathrm{L}$. Realizou-se as reações de cadeia utilizando-se de aparelho de termociclador para a desnaturação das fitas de DNA a $94^{\circ} \mathrm{C}$ durante 1 minuto, o anelamento a $45^{\circ} \mathrm{C}$ por 2 minutos e a extensão da fita a $74^{\circ} \mathrm{C}$ por 1,5 minuto, com um total de 33 ciclos, em que a desnaturação inicial ocorreu a $94^{\circ} \mathrm{C}$ por 3 minutos e a extensão final de $74^{\circ} \mathrm{C}$ durante 5 minutos. A revelação da amplificação foi realizada por eletroforese em gel de agarose e $1,5 \%$ de tampão Tris-Borato-EDTA 0,5\% (TBE- $54 \mathrm{~g}$ de Tris Base, 27,5 g de ácido bórico, $20 \mathrm{~mL}$ de EDTA 0,5 M, pH 8,0), em cuba de eletroforese a $80 \mathrm{~V}$ por uma hora e meia. Foi utilizada solução de Gelred no processo de coloração DNA e suas bandas para que este pudesse ser visível a luz ultravioleta por meio de um sistema de captação de imagem.

Para a realização do seqüenciamento, utilizou-se os iniciadores NL-1 e NL-4 da região D1/D2 da subunidade maior do gene do rRNA e eletroforese em gel de agarose a $1 \%$ : Para a reação de PCR foi utilizado $5 \mu \mathrm{L}$ de tampão $10 \mathrm{X}, 3,0 \mu \mathrm{L}$ de $\mathrm{MgCl} 2$ a $25 \mathrm{mM}, 2 \mu \mathrm{L}$ de dNTP $10 \mathrm{mM}, 1 \mu \mathrm{L}$ do iniciador NL1 $10 \mathrm{pmol}, 1 \mu \mathrm{L}$ do iniciador NL4 10 pmol, $0,2 \mu \mathrm{L}$ de taq DNA polimerase a $5,0 \mathrm{u} / \mu \mathrm{L}$ e 1 $\mu \mathrm{L}$ de DNA a 100-300 $\mathrm{ng} / \mu \mathrm{L}$, completando o volume final de $50 \mu \mathrm{L}$ com água ultrapura. A reação ocorreu em termocicladorsob desnaturação inicial a $95^{\circ} \mathrm{C}$ por 2 minutos, 35 ciclos de desnaturação a $95^{\circ} \mathrm{C}$ por 15 segundos, o anelamento a $54^{\circ} \mathrm{C}$ por 25 segundos e extensão a $72^{\circ} \mathrm{C}$ por 20 segundos, seguidos de extensão final a $72^{\circ} \mathrm{C}$ por 10 minutos. $\mathrm{O}$ resultado da reação foi revelado em eletroforese de gel de agarose $1,0 \%$ em tampão TBE $0,5 \%$ a 120 $\mathrm{V}$ durante 20 minutos e visualizado sob luz ultravioleta.

\section{c) Sequenciamento das Amostras}

As amostras foram enviadas para seqüenciamento no Laboratório de Ecologia, Taxonomia e Biotecnologia de Fungos da UFMG. Após o seqüenciamento os resultados foram comparados com as sequiências já existentes no GenBank utilizando-se do programa BLASTn, disponível no site www.ncbi.nlm.nih.gov/blast/,

\section{d) Caracterização do potencial de produção de enzimas hidrolíticas}

$\mathrm{O}$ teste para a produção das enzimas hidroliticas extracelulares foram realizados em placas de petri com meio de cultura mineral especifico (YNB, DIFCO). Foram realizados testes para as enzimas amilase, celulase, xilanase, lípase, protease e pectinases. O inoculo das leveduras tiveram suas concentrações da suspensão padronizadas mediada pela escala de Mac Farland $\mathrm{n}^{\mathrm{o}} 1$, com densidade ótica a $530 \mathrm{~nm}$, correspondente a presença de $3 \times 10^{8} \mathrm{UFC} / \mathrm{mL}$ para leveduras. O cálculo da atividade enzimática foi semiquantitativo utilizando o índice enzimático (IE) baseado no diâmetro médio do halo de degradação e o diâmetro médio da colônia. 


\section{e) Atividade lipolítica}

A produção de lipases foi realizada por meio do ensaio de formação de halos de hidrólise em meio sólido suplementado com óleo de oliva. Após 120 horas de incubação a $25^{\circ} \mathrm{C}$, a atividade lipolítica foi estimada pela razão entre o diâmetro do halo de hidrólise. As leveduras que apresentaram atividade lipolítica nos ensaios em meio sólido foram repicadas em meio YNB líquido acrescido de $2 \%$ de óleo de oliva por 72 horas sob agitação a $28^{\circ} \mathrm{C}$. Após centrifugação, o sobrenadante foi armazenado a $4^{\circ} \mathrm{C}$ até o momento da determinação de proteínas totais seguindo as recomendações de Bradford (1976), e da atividade lipolítica baseada na hidrólise do éster $p$-nitrofenilpalmitato ( $p$ NPP) em $p$ nitrofenol $(p N P)$ e ácido palmítico [15]. Os testes foram executados em placas com 96 poços e $10 \mu \mathrm{l}$ de amostra adicionados de $90 \mu \mathrm{l}$ de uma solução contendo $3 \mathrm{mg}$ de substrato (pNP) dissolvido em 1 $\mathrm{mL}$ de isopropanol misturado a $9 \mathrm{~mL}$ de $50 \mathrm{mM}$ Tris-HCl pH 8,0 contendo $40 \mathrm{mg}$ de Triton X-100 e $10 \mathrm{mg}$ de goma arábica. As placas foram incubadas em leitor de Elisa a $37^{\circ} \mathrm{C}$, e submetidas à leitura de absorvância a $410 \mathrm{~nm}$.

\section{f) Atividade proteolítica}

A metodologia para a determinação do potencial enzimático das leveduras seguiu as recomendações Ahearn et al. [15], que consiste em medir o halo de hidrólise da caseína em meio protease. As leveduras foram repicadas em Agar Sabouraud e incubadas em B.O.D a $25^{\circ} \mathrm{C}$ entre 24 a 48 horas. Após o crescimento foram inoculadas em placas de Petri (5 leveduras por placas), em meio protease ajustando o $\mathrm{pH}$ para 4.0, 7.0, $9.0 \mathrm{e}$ incubada a $25^{\circ} \mathrm{C}$ por até 72 horas. Após o crescimento foi realizado teste de hidrólise da caseína adicionando $\mathrm{HCl} 1 \mathrm{~N}$. Aquelas que formaram halo de hidrólise em torno da colônia foram consideradas proteolíticas.

\section{g) Carboximetilcelulase e xilanase}

A produção de carboximetilcelulase (CMcase) e xilanase foi realizada em meio contendo $1 \%$ de CMcase e xilana, respectivamente, como fonte de carbono. Após incubação, a capacidade carboximetilcelulolítica foi indicada por meio da técnica de coloração com vermelho Congo que de acordo com Teather \& Wood [16], este corante pode interagir com uma grande quantidade de polissacarídeos, viabilizando assim, a visualização do halo de degradação. Por sua vez, a produção de xilanase foi identificada com base na presença de halos claros em torno das colônias, que foram medidos com auxílio de paquímetro digital.

\section{RESULTADOS E DISCUSSÃO}

\section{a) Potencial para a produção das enzimas protease, lipase, (CMcase) e xilanase a partir das linhagens isoladas.}

Segundo Leite et al. [17] (2008), a necessidade de testar enzimas brutas representa grande aplicação biológica uma vez que a utilização de enzimas puras pode ser inviável. Para se verificar a produção de proteases, lipase e celulase (CMcase), as placas foram avaliadas quanto a produção de halos, pois as colônias que crescem de maneira isolada, apresentam halos que podem ser dimensionados através do Índice Enzimático de Atividade (IAE). Para a atividade proteolítica, foram realizados os testes em diferentes $\mathrm{pH}$ dos 84 isolados testados. Em meio ácido $(\mathrm{pH} 4,0), 31$ isolados apresentaram resultados positivos nos testes (formação de halo) de 0,15 a 0,60 mm. Em meio neutro $(\mathrm{pH} \mathrm{7,0),} 38$ isolados apresentaram formação de halo de 0,29 a 0,54. Em meio básico ( $\mathrm{pH} 9,0)$, apenas 21 isolados apresentaram resultados positivos, sendo que os halos se mantiveram entre 0,13 a $0,56 \mathrm{~mm}$ (Tabela 1).

Tabela 1. Resultados de atividade proteolítica das leveduras, crescimento em meio protease em diferentes pH à temperatura $25^{\circ} \mathrm{C} / 72$ horas.

\begin{tabular}{ccccc}
\hline \multirow{2}{*}{ Código } & Identificação & \multicolumn{3}{c}{$\mathrm{pH}$} \\
\cline { 3 - 4 } PB 001 & $*$ & 4,00 & 7,00 & 9,00 \\
PB 002 & $*$ & - & + & - \\
PB 003 & $*$ & - & - & - \\
PB 004 & $*$ & + & + & - \\
PB 006 & $*$ & - & + & - \\
PB 008 & $*$ & - & - & - \\
PB 012 & $*$ & - & - & + \\
PB 013 & $*$ & - & + & + \\
PB 015 & $*$ & - & + & + \\
\hline
\end{tabular}

"Continua" 
Tabela 1. "Continua"

\begin{tabular}{|c|c|c|c|c|}
\hline \multirow{2}{*}{ Código } & \multirow{2}{*}{ Identificação } & \multicolumn{3}{|c|}{$\mathrm{pH}$} \\
\hline & & 4,00 & 7,00 & 9,00 \\
\hline PB 017 & $*$ & - & + & - \\
\hline PB 018 & * & + & + & - \\
\hline PB 019 & $*$ & - & - & - \\
\hline PB 020 & Pichia guilliermondii & - & + & + \\
\hline PB 021 & Candida bombicola & - & + & + \\
\hline PB 022 & Candida bombicola & - & + & + \\
\hline PB 023 & Candida parapsilosis & - & + & + \\
\hline PB 024 & Cryptococcus buthanensis & & & \\
\hline PB 025 & Candida bombicola & - & - & - \\
\hline PB 026 & Pichia guilliermondii & - & - & - \\
\hline PB 027 & Candida parapsilosis & - & - & - \\
\hline PB 028 & Pichia guilliermondii & - & + & - \\
\hline PB 029 & Metschnikowia reukaufii & - & - & - \\
\hline PB 030 & Candida bombicola & - & - & - \\
\hline PB 031 & Cryptococcus buthanensis & + & + & - \\
\hline PB 032 & Pichia kluyveri & + & - & - \\
\hline PB 033 & Pichia guilliermondii & + & + & - \\
\hline PB 034 & Pichia membraniefaciens & + & + & - \\
\hline PB 036 & Pichia kluyveri & + & - & - \\
\hline PB 037 & Pichia kluyveri & + & + & - \\
\hline PB 038 & Kloeckera apis & - & + & - \\
\hline PB 039 & Starmerella bombicola & - & - & - \\
\hline PB 040 & Candida parapsilosis & - & - & - \\
\hline PB 041 & Metschnikowia reukaufii & + & - & - \\
\hline PB 042 & Candida gropengiesseri & - & - & - \\
\hline PB 043 & Candida gropengiesseri & - & - & - \\
\hline PB 044 & Starmerella bombicola & + & - & + \\
\hline PB 045 & Candida bombicola & + & - & - \\
\hline PB 046 & Candida gropengiesseri & + & + & + \\
\hline PB 047 & Pichia membraniefaciens & + & - & - \\
\hline PB 048 & Candida parapsilosis & + & + & + \\
\hline PB 049 & Starmerella bombicola & + & - & + \\
\hline PB 050 & Metschnikowia reukaufii & + & + & - \\
\hline PB 051 & Starmerella bombicola & + & - & + \\
\hline PB 052 & Candida gropengiesseri & - & - & - \\
\hline PB 053 & Pichia guilliermondii & - & - & - \\
\hline PB 054 & Candida parapsilosis & - & - & - \\
\hline PB 055 & Pichia guilliermondii & - & + & - \\
\hline PB 057 & Aureobasidium pullulans & - & + & + \\
\hline PB 060 & * & + & - & + \\
\hline PB 062 & $*$ & + & - & - \\
\hline PB 063 & $*$ & + & + & - \\
\hline PB 065 & $*$ & + & + & + \\
\hline PB 066 & $*$ & + & + & - \\
\hline PB 067 & $*$ & - & - & - \\
\hline PB 068 & $*$ & + & - & + \\
\hline PB 069 & * & - & - & - \\
\hline PB 070 & $*$ & + & - & - \\
\hline PB 071 & * & - & - & - \\
\hline PB 072 & $*$ & - & + & + \\
\hline PB 073 & $*$ & + & - & - \\
\hline PB 074 & $*$ & - & + & + \\
\hline PB 075 & $*$ & - & + & + \\
\hline PB 076 & $*$ & - & + & + \\
\hline PB 077 & $*$ & - & - & + \\
\hline PB 078 & * & - & + & + \\
\hline PB 079 & $*$ & - & + & + \\
\hline
\end{tabular}

"Continua" 
Tabela 1. "Conclusão"

\begin{tabular}{lcccc}
\hline Código & Identificação & & $\mathrm{pH}$ & \\
\cline { 3 - 4 } PB 080 & $*$ & 4,00 & 7,00 & 9,00 \\
PB 081 & $*$ & + & - & - \\
PB 082 & $*$ & + & - & + \\
PB 083 & $*$ & - & - & + \\
PB 084 & $*$ & + & - & + \\
PB 085 & $*$ & - & + & + \\
PB 086 & $*$ & + & - & + \\
PB 088 & $*$ & + & + & - \\
PB 089 & $*$ & - & + & - \\
PB 090 & $*$ & - & - & - \\
PB 091 & $*$ & + & - & + \\
PB 092 & $*$ & - & + & + \\
PB 093 & $*$ & - & + & + \\
PB 094 & $*$ & - & + & + \\
PB 095 096 & $*$ & - & - \\
PB 097 & $*$ & - & - \\
\hline
\end{tabular}

*Sem identidade por se tratar de isolados agrupados

Destas, seis linhagens apresentaram atividade proteolítica em todos os valores de $\mathrm{pH}$ testados; e 30 linhagens apresentaram atividade proteolítica em dois valores de $\mathrm{pH}$. A maioria destas (15 linhagens ou 50\%) apresentaram atividade em $\mathrm{pH}$ neutro ou alcalino. Nove linhagens apresentaram atividade em $\mathrm{pH}$ neutro e ácido, e somente seis linhagens apresentaram atividade em $\mathrm{pH}$ alcalino e ácido, mas não em pH neutro. Apenas 22 linhagens $(26,2 \%)$ não apresentaram atividade proteolítica.
Para a atividade lipolítica, dos 84 isolados, 62 $(73,8 \%)$ apresentaram formação de halo e índices de atividade enzimática entre 0,17 a $0,67(\mathrm{~mm})$ (Tabela 2). Segundo Gonçalves [18], a atividade lipásica é detectada quando em meio sólido contendo substrato específico, ocorre a formação de halo, quando os corantes reagem com os ácidos graxos.

Tabela 2. Resultados de atividade lipolítica das leveduras, após 120 horas de incubação a $25^{\circ} \mathrm{C}$, a atividade lipolítica foi estimada pela razão entre o diâmetro do halo de hidrólise.

\begin{tabular}{lccccc}
\hline Código & Identificação & DC $(\mathbf{m m})$ & DH $(\mathbf{m m})$ & IAE & $\begin{array}{c}\text { Atividade } \\
\text { lipolítica }\end{array}$ \\
\hline PB 001 & $*$ & 15 & 38 & 0,39 & + \\
PB 002 & $*$ & - & - & - & - \\
PB 003 & $*$ & 10 & 34 & 0,29 & + \\
PB 004 & $*$ & 11 & 39 & 0,28 & + \\
PB 006 & $*$ & 11 & 42 & 0,26 & + \\
PB 008 & $*$ & - & - & - & - \\
PB 012 & $*$ & - & - & - & - \\
PB 013 & $*$ & - & 13 & 0,54 & + \\
PB 015 & $*$ & - & - & - & - \\
PB 017 & $*$ & 15 & 40 & 0,38 & + \\
PB 018 & $*$ & 30 & 58 & 0,52 & + \\
PB 019 & * & - & - & 0,4 & + \\
PB 020 & Pichia guilliermondii & 9 & 30 & - & - \\
PB 021 & Candida bombicola & - & - & - & + \\
PB 022 & Candida bombicola & 13 & 44 & 0,34 & - \\
PB 023 & Candida parapsilosis & 8 & 27 & 0,3 & + \\
PB 025 & Cryptococcus buthanensis & 10 & 26 & 0,38 & + \\
PB 026 & Candida bombicola & & & & + \\
\hline Conting & & & & & + \\
\hline
\end{tabular}

"Continua” 
Tabela 2. "Continua"

\begin{tabular}{|c|c|c|c|c|c|}
\hline Código & Identificação & $\mathrm{DC}(\mathbf{m m})$ & DH (mm) & IAE & $\begin{array}{l}\text { Atividade } \\
\text { lipolítica }\end{array}$ \\
\hline PB 027 & Pichia guilliermondii & - & - & - & - \\
\hline PB 028 & Candida parapsilosis & - & - & - & - \\
\hline РВ 029 & Pichia guilliermondii & 8 & 24 & 0,33 & + \\
\hline PB 030 & Metschnikowia reukaufii & 12 & 18 & 0,67 & + \\
\hline PB 031 & Candida bombicola & 18 & 46 & 0,39 & + \\
\hline PB 032 & Cryptococcus buthanensis & 14 & 40 & 0,35 & + \\
\hline РB 033 & Pichia kluyveri & 13 & 42 & 0,31 & + \\
\hline PB 034 & Pichia guilliermondii & 13 & 41 & 0,32 & + \\
\hline PB 036 & Pichia membraniefaciens & - & - & - & - \\
\hline PB 037 & Pichia kluyveri & 24 & 56 & 0,43 & + \\
\hline PB 038 & Pichia kluyveri & - & - & - & - \\
\hline РВ 039 & Kloeckera apis & - & - & - & - \\
\hline РB 040 & Starmerella bombicola & 8 & 22 & 0,36 & + \\
\hline РB 041 & Candida parapsilosis & 10 & 40 & 0,25 & + \\
\hline PB 042 & Metschnikowia reukaufii & 19 & 52 & 0,37 & + \\
\hline РB 043 & Candida gropengiesseri & 5 & 18 & 0,28 & + \\
\hline PB 044 & Candida gropengiesseri & 15 & 44 & 0,34 & + \\
\hline PB 045 & Starmerella bombicola & 8 & 30 & 0,27 & + \\
\hline РB 046 & Candida bombicola & 10 & 30 & 0,33 & + \\
\hline РB 047 & Candida gropengiesseri & 9 & 30 & 0,3 & + \\
\hline PB 048 & Pichia membraniefaciens & 12 & 33 & 0,36 & + \\
\hline РВ 049 & Candida parapsilosis & 12 & 36 & 0,33 & + \\
\hline РB 050 & Starmerella bombicola & 11 & 34 & 0,32 & + \\
\hline PB 051 & Metschnikowia reukaufii & 12 & 30 & 0,4 & + \\
\hline РB 052 & Starmerella bombicola & 10 & 28 & 0,36 & + \\
\hline PB 053 & Candida gropengiesseri & 14 & 23 & 0,6 & + \\
\hline РB 054 & Pichia guilliermondii & 9 & 24 & 0,37 & + \\
\hline PB 055 & Candida parapsilosis & 10 & 20 & 0,5 & + \\
\hline PB 056 & Pichia guilliermondii & 11 & 21 & 0,52 & + \\
\hline РB 057 & Aureobasidium pullulans & 20 & 50 & 0,4 & + \\
\hline PB 060 & $*$ & 7 & 24 & 0,29 & + \\
\hline PB 062 & * & 8 & 23 & 0,35 & + \\
\hline РB 063 & * & 9 & 25 & 0,36 & + \\
\hline PB 065 & $*$ & - & - & - & - \\
\hline PB 066 & $*$ & - & - & - & - \\
\hline PB 067 & $*$ & - & - & - & - \\
\hline РB 068 & * & 8 & 28 & 0,29 & + \\
\hline PB 069 & $*$ & - & - & - & - \\
\hline РB 070 & * & 15 & 46 & 0,33 & + \\
\hline РB 071 & * & 11 & 33 & 0,33 & + \\
\hline РB 072 & $*$ & 10 & 29 & 0,34 & + \\
\hline РВ 073 & * & 7 & 40 & 0,17 & + \\
\hline PB 074 & $*$ & 9 & 23 & 0,39 & + \\
\hline PB 075 & $*$ & 9 & 34 & 0,26 & + \\
\hline РВ 076 & $*$ & 8 & 17 & 0,47 & + \\
\hline PB 077 & $*$ & - & - & - & - \\
\hline
\end{tabular}

"Continua" 
Tabela 2. "Conclusão"

\begin{tabular}{lccccc}
\hline Código & Identificação & DC (mm) & DH (mm) & IAE & $\begin{array}{c}\text { Atividade } \\
\text { lipolítica }\end{array}$ \\
\hline PB 078 & $*$ & 8 & 40 & 0,2 & + \\
PB 079 & $*$ & - & - & - & + \\
PB 080 & $*$ & 8 & 29 & 0,28 & + \\
PB 081 & $*$ & 11 & 40 & 0,28 & + \\
PB 082 & $*$ & 8 & 28 & 0,29 & + \\
PB 083 & $*$ & 7 & 36 & 0,19 & + \\
PB 084 & $*$ & 8 & 26 & 0,31 & + \\
PB 085 & $*$ & - & - & - & + \\
PB 086 & $*$ & 8 & 28 & 0,29 & + \\
PB 087 & $*$ & 7 & 30 & 0,23 & + \\
PB 088 & $*$ & 8 & 38 & 0,21 & + \\
PB 089 & $*$ & 11 & 50 & 0,22 & + \\
PB 090 & $*$ & - & - & - \\
PB 091 & $*$ & 7 & 22 & 0,32 & + \\
PB 092 & $*$ & 11 & 31 & 0,35 & + \\
PB 093 & $*$ & 18 & 45 & - & + \\
PB 094 & $*$ & - & - & - \\
PB 095 & $*$ & 20 & 56 & - & + \\
PB 096 & $*$ & - & - & + \\
PB 097 & $*$ & - & +
\end{tabular}

*Sem identidade por se tratar de isolados agrupados

Já para a produção de CMcase, apenas 18 índices enzimáticos se mantiveram entre 0,21 e 0,58 linhagens formaram halos de degradação, e os $(\mathrm{mm})$ (Tabela 3).

Tabela 3. Resultados de atividade de CMCase das linhagens de leveduras isoladas de amêndoas de babaçu

\begin{tabular}{lccccc}
\hline Código & Identificação & DC $(\mathrm{mm})$ & DH $(\mathrm{mm})$ & IAE & $\begin{array}{c}\text { Atividade } \\
\text { CMcase }\end{array}$ \\
\hline PB 001 & $*$ & - & - & - & - \\
PB 002 & $*$ & - & - & - & - \\
PB 003 & $*$ & - & - & - & - \\
PB 004 & $*$ & - & - & - & - \\
PB 006 & $*$ & - & - & - & - \\
PB 008 & $*$ & - & - & - & - \\
PB 012 & $*$ & - & - & - & - \\
PB 013 & $*$ & - & - & - & - \\
PB 015 & $*$ & - & - & - & - \\
PB 017 & $*$ & - & - & - & - \\
PB 018 & $*$ & - & - & - & - \\
PB 019 & $*$ & - & - & - & - \\
PB 020 & Pichia guilliermondii & - & - & - & - \\
PB 021 & Candida bombicola & - & - & - & - \\
PB 022 & Candida bombicola & - & - & - & - \\
PB 023 & Candida parapsilosis & - & - & - & - \\
PB 025 & Cryptococcus buthanensis & - & - & - & + \\
PB 026 & Candida bombicola & 7 & 17 & 0,41 & \\
\hline
\end{tabular}

"Continua” 
Tabela 3. "Continua"

\begin{tabular}{|c|c|c|c|c|c|}
\hline Código & Identificação & $\mathrm{DC}(\mathrm{mm})$ & $\mathrm{DH}(\mathrm{mm})$ & IAE & $\begin{array}{l}\text { Atividade } \\
\text { CMcase }\end{array}$ \\
\hline PB 027 & Pichia guilliermondii & - & - & - & - \\
\hline PB 028 & Candida parapsilosis & - & - & - & - \\
\hline PB 029 & Pichia guilliermondii & - & - & - & - \\
\hline PB 030 & Metschnikowia reukaufii & - & - & - & - \\
\hline PB 031 & Candida bombicola & 5 & 18 & 0,28 & + \\
\hline PB 032 & Cryptococcus buthanensis & - & - & - & - \\
\hline PB 033 & Pichia kluyveri & 6 & 13 & 0,46 & + \\
\hline PB 034 & Pichia guilliermondii & 5 & 17 & 0,29 & + \\
\hline PB 036 & Pichia membraniefaciens & - & - & - & - \\
\hline PB 037 & Pichia kluyveri & - & - & - & - \\
\hline PB 038 & Pichia kluyveri & - & - & - & - \\
\hline PB 039 & Kloeckera apis & - & - & - & - \\
\hline PB 040 & Starmerella bombicola & - & - & - & - \\
\hline PB 041 & Candida parapsilosis & - & - & - & - \\
\hline PB 042 & Metschnikowia reukaufii & - & - & - & - \\
\hline PB 043 & Candida gropengiesseri & - & - & - & - \\
\hline PB 044 & Candida gropengiesseri & - & - & - & - \\
\hline PB 045 & Starmerella bombicola & 8 & 16 & 0,5 & + \\
\hline PB 046 & Candida bombicola & 6 & 11 & 0,55 & + \\
\hline PB 047 & Candida gropengiesseri & 6 & 14 & 0,43 & + \\
\hline PB 048 & Pichia membraniefaciens & 5 & 17 & 0,29 & + \\
\hline PB 049 & Candida parapsilosis & 4 & 15 & 0,27 & + \\
\hline PB 050 & Starmerella bombicola & - & - & - & - \\
\hline PB 051 & Metschnikowia reukaufii & 5 & 10 & 0,5 & + \\
\hline PB 052 & Starmerella bombicola & - & - & - & - \\
\hline PB 053 & Candida gropengiesseri & - & - & - & - \\
\hline PB 054 & Pichia guilliermondii & - & - & - & - \\
\hline PB 055 & Candida parapsilosis & - & - & - & - \\
\hline PB 056 & Pichia guilliermondii & 4 & 19 & 0,21 & + \\
\hline PB 057 & Aureobasidium pullulans & - & - & - & - \\
\hline PB 060 & $*$ & - & - & - & - \\
\hline PB 062 & $*$ & - & - & - & - \\
\hline PB 063 & $*$ & 7 & 12 & 0,58 & + \\
\hline PB 065 & $*$ & - & - & - & - \\
\hline PB 066 & $*$ & 6 & 14 & 0,43 & + \\
\hline PB 067 & $*$ & 6 & 15 & 0,4 & + \\
\hline PB 068 & $*$ & - & - & - & - \\
\hline PB 069 & $*$ & - & - & - & - \\
\hline PB 070 & $*$ & 6 & 17 & 0,35 & + \\
\hline PB 071 & * & - & - & - & - \\
\hline PB 072 & $*$ & - & - & - & - \\
\hline PB 073 & $*$ & 4 & 19 & 0,21 & + \\
\hline PB 074 & $*$ & - & - & - & - \\
\hline PB 075 & $*$ & - & - & - & - \\
\hline PB 076 & $*$ & - & - & - & - \\
\hline PB 077 & $*$ & - & - & - & - \\
\hline
\end{tabular}

"Continua” 
Tabela 3. "Conclusão"

\begin{tabular}{cccccc}
\hline Código & Identificação & DC $(\mathrm{mm})$ & DH $(\mathrm{mm})$ & IAE & $\begin{array}{c}\text { Atividade } \\
\text { CMcase }\end{array}$ \\
\hline PB 078 & $*$ & - & - & - & - \\
PB 079 & $*$ & - & - & - & - \\
PB 080 & $*$ & - & - & - & - \\
PB 081 & $*$ & 5 & 14 & 0,36 & + \\
PB 082 & $*$ & - & - & - & - \\
PB 083 & $*$ & - & - & - & - \\
PB 084 & $*$ & - & - & - & - \\
PB 085 & $*$ & - & - & - & - \\
PB 086 & $*$ & - & 17 & 0,47 & + \\
PB 087 & $*$ & - & - & - & - \\
PB 088 & $*$ & - & - & - & - \\
PB 089 & $*$ & - & - & - & - \\
PB 090 & $*$ & - & - & - & - \\
PB 091 & $*$ & - & - & - & - \\
PB 092 & $*$ & - & - & - & - \\
PB 093 & $*$ & - & - & - & - \\
PB 094 & $*$ & - & - & - & - \\
PB 095 & $*$ & - & - & - & - \\
PB 096 & $*$ & - & - & - & - \\
PB 097 & $*$ & - & - & - & \\
\hline
\end{tabular}

*Sem identidade por se tratar de isolados agrupados

Não houve produção de xilanase, o que configura que os isolados não apresentam boa capacidade de hidrolisar compostos lignocelósicos, resultados esses que corroboram com os encontrados por Motta e Filho [19], que ao analisar um total de 349 leveduras selvagens, apenas duas linhagens se apresentaram como boas produtoras de xilanase (testes realizados em dois meios de cultura distintos). Segundo Lealem e Gashe [20], para um microrganismo ser considerado um bom produtor de enzimas em meio sólido seu índice enzimático (IE), tem que ser maior ou igual a 2,0. Os valores encontrados neste estudo todos se mantiveram abaixo de 2,0, este resultado pode ser atribuído ás condições dos testes uma vez que as linhagens poderiam apresentar um índice enzimático maior em outras condições.

\section{b) Identidade molecular das espécies de leveduras das amêndoas do babaçu}

As linhagens de leveduras isoladas de amêndoas de babaçu foram submetidas a agrupamento a partir do perfil por PCR fingerprinting. De acordo com o agrupamento por PCR fingerprinting com o iniciador EI1; os 84 isolados de leveduras foram agrupados em 38 grupos (Tabela 4). Estes 38 grupos identificados em 8 gêneros e 12 espécies de leveduras.

Tabela 4. Resultado do sequenciamento das leveduras encontradas nas amêndoas do babaçu e as características morfológicas das colônias de cada isolado.

\begin{tabular}{lccccc}
\hline \multirow{2}{*}{ Código } & \multirow{2}{*}{ Identificação } & \multicolumn{4}{c}{ Descrição morfológica } \\
\cline { 3 - 6 } & & Cor & Borda & Elevação & Textura \\
\hline PB20 & Pichia guilliermondii & Creme & Lisa & Achatada & Opaca \\
PB21 & Candida bombicola & Branca & Lisa & Levemente elevada & Brilhante \\
PB22 & Candida bombicola & Branca & Lisa & Levemente elevada & Brilhante \\
PB23 & Candida parapsilosis & Branca & Lisa & Levemente elevada & Brilhante \\
PB24 & Cryptococcus buthanensis & Creme & Lisa & Achatada & Brilhante \\
PB25 & Candida bombicola & Branca & Lisa & Levemente elevada & Brilhante \\
\hline
\end{tabular}

"Continua" 
Tabela 4. "Conclusão"

\begin{tabular}{|c|c|c|c|c|c|}
\hline \multirow{2}{*}{ Código } & \multirow{2}{*}{ Identificação } & \multicolumn{4}{|c|}{ Descrição morfológica } \\
\hline & & Cor & Borda & Elevação & Textura \\
\hline PB26 & Pichia guilliermondii & Creme & Lisa & Levemente elevada & Opaca \\
\hline PN27 & Candida parapsilosis & Branca & Lisa & Achatada & Brilhante \\
\hline PB28 & Pichia guilliermondii & Creme & Lisa & Levemente elevada & Brilhante \\
\hline PB29 & Metschnikowia reukaufii & Creme & Lisa & Acuminada & Opaca \\
\hline PB30 & Candida bombicola & Branca & Lisa & Levemente elevada & Opaca \\
\hline PB31 & Cryptococcus buthanensis & Creme & Lisa & Achatada & Brilhante \\
\hline PB32 & Pichia kluyveri & Creme & Lisa & Levemente elevada & Brilhante \\
\hline PB33 & Pichia guilliermondii & Branca & Lisa & Acuminada & Brilhante \\
\hline PB34 & Pichia membraniefaciens & Creme & Lisa & Achatada & Opaca \\
\hline PB35 & Candida bombicola & Branca & Lisa & Levemente elevada & Opaca \\
\hline PB36 & Pichia kluyveri & Creme & Lisa & Levemente elevada & Brilhante \\
\hline PB37 & Pichia kluyveri & Creme & Lisa & Levemente elevada & Brilhante \\
\hline PB38 & Kloeckera apis & Branca & Lisa & Achatada & Brilhante \\
\hline PB39 & Starmerella bombicola & Creme & Rugosa & Levemente elevada & * \\
\hline PB40 & Candida parapsilosis & Branca & Lisa & Achatada & Brilhante \\
\hline PB41 & Metschnikowia reukaufii & Creme & Lisa & Achatada & Brilhante \\
\hline PB42 & Candida gropengiesseri & Branca & Lisa & Levemente elevada & Brilhante \\
\hline PB43 & Candida gropengiesseri & Branca & Lisa & Levemente elevada & Brilhante \\
\hline PB44 & Starmerella bombicola & Creme & Rugosa & Levemente elevada & Opaca \\
\hline PB45 & Candida bombicola & Branca & Rugosa & Levemente elevada & Opaca \\
\hline PB46 & Candida gropengiesseri & Creme & Lisa & Levemente elevada & Brilhante \\
\hline PB47 & Pichia membraniefaciens & Creme & Lisa & Achatada & Opaca \\
\hline PB48 & Candida parapsilosis & Branca & Lisa & Achatada & * \\
\hline PB49 & Starmerella bombicola & Creme & Rugosa & Levemente elevada & Opaca \\
\hline PB50 & Metschnikowia reukaufii & Creme & Lisa & Achatada & Opaca \\
\hline PB51 & Starmerella bombicola & Creme & Rugosa & Levemente elevada & Opaca \\
\hline PB52 & Candida gropengiesseri & Creme & Lisa & Achatada & Opaca \\
\hline PB53 & Pichia guilliermondii & Branca & Lisa & Levemente elevada & Opaca \\
\hline PB54 & Candida parapsilosis & Branca & Lisa & Achatada & Brilhante \\
\hline PB55 & Pichia guilliermondii & Branca & Lisa & Achatada & Opaca \\
\hline PB56 & Rhodotorula mucilaginosa & Vermelha & Lisa & Aculminada & Opaca \\
\hline PB57 & Aureobasidium pullulans & Creme & Rugosa & Achatada & Opaca \\
\hline
\end{tabular}

*Características não registradas

As espécies Pichia guilliermondii e Candida bombicola foram as mais frequentes em ocorrência nas amêndoas de babaçu, com 6 linhagens cada uma; seguidas de Candida parapsilosis com 5 linhagens; Starmerella bombicola e Candida gropengiesseri com 4 linhagens cada; Metschnikowia reukaufii e Pichia kluyveri com 3 linhagens para cada espécie. Cryptococcus buthanensis e Pichia membraniefaciens foram representadas por dois isolados e Aureobasidium pullulans, Rhodotorula mucilaginosa e Kloeckera apis foram isolados somente uma vez. 
As linhagens proteolíticas sequenciadas pertecem a 13 espécies, sendo que as espécies Candida bombicola, Pichia guilliermondii, $P$. kluyveri e Starmerella bombicola apresentaram 3 linhagens proteolíticas cada. Metschnikowia reukauffi e $P$. membraniefaciens apresentaram duas linhagens proteolíticas. Interessante é notar que a atividade proteolítica não é uma característica espécie-específica, já que algumas espécies de leveduras apresentaram linhagens produtoras e outras linhagens não produtoras de proteases.

Também a atividade lipolítica ocorreu em algumas linhagens, mas não todas as linhagens das espécies $P$. guilliermondii, $C$. bombicola e $C$. parapsilosis, indicando que a atividade lipolítica não é espécie-específica em leveduras.

\section{CONCLUSÃO}

As leveduras isoladas das amêndoas de castanha do babaçu da região de Araguaína do Tocantins, obtidas a partir das quebradeiras de coco da região mostraram potencial para produção de

\section{REFERÊNCIAS}

[1]. SANTOS, N. A. DOS. Propriedades termooxidativas e de fluxo do biodiesel de Babaçu (Orbignya phalerata), Universidade Federal da Paraíba, 2008. (Dissertação de Mestrado em Química).

[2]. RIBEIRO, J.F. \& WALTER, B.M.T. Fitofiosionomias do bioma Cerrado. In Cerrado: ambiente e flora (eds S.M. Sano \& S.P. Almeida), EMBRAPA -CPAC. Planaltina, p. 87-166, 1998.

[3]. ROSENTHAL, F. R. T. O amido do coco de babaçu, algumas propriedades dos grânulos e das pastas. Revista Brasileira de Tecnologia, v.6, p.29-33, 1975.

[4]. LORENZI, H.; SOUZA, H.M.; MEDEIROSCOSTA, J.T.; CERQUEIRA, L.S.C.; BEHR, N. von. Palmeiras do Brasil: nativas e exóticas. Nova Odessa: Plantarum, 303 p., 1996.

[5]. MILLER, M. W. Yeasts in food spoilage and update. Food Technology, Chicago, v.33, p.76-80, 1979.

[6]. LACHANCE, M. A. AND STARMER, W. T. Ecology and Yeasts.. In Kurtzman C.W. and J. W. Fell, 1998.The Yeasts: A Taxonomic Study.4th ed, p. 21-30 Elsevier, 1998.

[7]. THOMAS, P.; SOLY, T. A. Endophytic bacteria associated with growing shoot tips of banana (Musa sp.) cv. Grand Naine and the affinity of Endophytes to the Host. Microbial Ecology, v.58, n.4, p.952964, 2009. http://dx.doi.org/10.1007/s00248-0099559-z enzimas. Uma porcentagem significante de isolados conseguiram hidrolisar a caseína em meio protease nos diferentes $\mathrm{pH}$ testados, até mesmo em meio ácido. Estas leveduras também apresentaram ótimos resultados com relação a atividade lipolítica pois de todas as linhagens testadas a maioria produziram lípases. Porém estas leveduras não apresentaram bons resultados com relação a atividade celulolítica. Apenas algumas linhagens mostraram atividade de degradação da celulose.

\section{CONTRIBUIÇÃO DOS AUTORES}

1. Elaboração da pesquisa, condução e orientação dos experimentos e identificação de leveduras:

\section{Dra ${ }^{\mathrm{a}}$. Paula Benevides de Morais}

2. Análise de dados, redação e revisão final do artigo

\author{
Ana Paula Martins Guimarães \\ Stella Costa Santos do Vale \\ Dr $^{\text {a }}$. Paula Benevides de Morais
}

[8]. SILVA, J. J. I. Ocorrência e diversidade de leveduras no filoplano de plantas selecionadas do Parque Nacional da Serra da Arrábida. Faculdade de Ciências e Tecnologia da Universidade Nova de Lisboa. 2003 http://run.unl.pt/handle/10362/1902,. (Tese de Doutorado em Biologia).

[9]. ARAÚJO, M. A. M. de. Isolamento de leveduras para a produção de enzimas de interesse industrial a partir de frutos do Cerrado. Dissertação (mestrado em biotecnologia). Universidade Católica Dom Bosco, Campo Grande, 2015.

[10]. YARROW, D. Methods for the isolation, maintainance and identification of yeasts. In: The Yeasts, a taxonomic study. 4th Ed (Kutzman, CP and Fell, JW, eds), Amsterdam, p. 77-100. Elsevier Science BV, 1998.

[11]. KIRSOP, B. E. C. P. KURTZMAN, eds. Living Resources for Biotechnology: Yeasts. Cambridge University Press, 234 p., 1988.

[12]. QUEROL, A. et al. Molecular monitoring of wine fermentations conducted by active dry yeasts strains. Applied and Environmental Microbiology, Valencia, v.58, p.2948-2593, 1992.

[13]. DE BARROS L. M.; SODEN, A.; HENSCHKE, P. A.; LANGRIDGE, P. PCR differentiation of commercial yeasts strains using intron splice site primers. Applied and Environmental Microbiology, v.62, p.4514-4520, 1996.

[14]. WINKLER, U. K.; STUCKMANN, M. Glycogen, hyaluronate, and some other polysaccharides greatly enhance the formation of 
exolipase by Serratia marcescens. Journal of bacteriology, v.138, n.3, p.663-670, 1979.

[15]. AHEARN, D. G., F. J. Roth, Jr., and S. P. Ecology and characterization of yeasts from aquatic regions of South Florida. Marine Biology, Meyers, v.1, p.291-308, 1968. http://dx.doi.org/10.1007/BF00360780

[16]. TEATHER R. M. \& WOOD P. J. Use of Congo Red-Polysaccharide interactions in enumeration and characterization of cellulolytic bacteria from the bovine rumen. Applied and Environmental Microbiology, v.4, p.777-780, 1982.

[17]. LEITE, R. S.R; ALVES-PRADO H. F.; CABRAL, H; PAGNOCCA, F. C.; GOMES, E.; SILVA, R. da. Production and characteristics comparison of crude $\beta$-glucosidases produced by microorganisms Thermoascus aurantiacus e Aureobasidium pullulans in agricultural wastes.
Enzyme and Microbial Technology, v.43, p.391395, 2008. http://dx.doi.org/10.1016/j.enzmictec.2008.07.006

[18]. GONÇALVES, F. A. G., Produção de lipase extracelular por leveduras em cultivo submerso. Belo Horizonte: Faculdade de Farmácia da UFMG. 2007. 66p. (Dissertação, Mestrado em Ciência de Alimentos).

[19]. MOTTA, F. B.; FILHO, F. M.; Triagem, seleção, produção e caracterização da enzima xilanase a partir de leveduras silvestres. Universidade Estadual de Campinas -UNICAMP, 2008. (Disssertação de Mestrado em Engenharia de Alimentos).

[20]. LEALEM, F.; GASHE, B. A. Amylase production by a gram-positive bacterium isolated from fermenting tef (Eraglostistef). Journal of Bacteriology, Danvers, v.77, n.3 p.348-352, 1994. 